\title{
Analisis Perbandingan Algoritma Penjadwalan CPU First Come First Serve (FCFS) Dan Round Robin
}

\author{
Muhammad Taufik Dwi Putra*, Haryanto Hidayat, Naziva Septian, Tiara Afriani \\ Fakultas Kampus UPI di Cibiru, Prodi Teknik Komputer, Universitas Pendidikan Indonesia, Bandung, Indonesia \\ Email: 1," tdputra@upi.edu, ${ }^{2}$ haryanto@upi.edu, ${ }^{3}$ nazivaseptian26@upi.edu, ${ }^{4}$ tiaraafriani@upi.edu \\ Email Penulis Korespondensi: tdputra@upi.edu \\ Submitted: 16/12/2021; Accepted: 26/12/2021; Published: 31/12/2021
}

\begin{abstract}
Abstrak-Penjadwalan CPU merupakan hal yang penting dalam multitasking dan multiprocessing sebuah sistem operasi karena banyaknya proses yang perlu dijalankan dalam komputer. Hal tersebut menyebabkan sistem operasi perlu membagi sumber daya untuk proses-proses yang berjalan. Penjadwalan CPU memiliki beberapa algoritma didalamnya seperti algoritma First Come First Serve (FCFS), Shortest Job First (SJF), Priority Scheduling, dan Round Robin (RR). Penulisan dari penelitian ini dimaksudkan untuk membandingkan algoritma First Come First Serve dan Round Robin dengan empat parameter yang ditentukan yaitu Average Turn Around Time, Waiting Time, Throughput, dan CPU Utilization. Percobaan dilakukan dengan Algoritma First Come First Serve dan Round Robin dari tiga Quantum Time yang berbeda. Perhitungan pada quantum time yang berbeda ini bertujuan untuk mengetahui apakah perbedaan tersebut memengaruhi keunggulan algoritma Round Robin terhadap algoritma First Come First Serve. Dari Hasil penelitian ini kesimpulan yang didapatkan adalah bahwa algoritma First Come First Serve (FCFS) lebih unggul dari algoritma Round Robin (RR). Hal tersebut ditunjukkan dengan nilai rata-rata Turn Around Time, Waiting Time, dan Throughput dari algoritma First Come First Serve lebih efektif dalam menjalankan proses.
\end{abstract}

Kata Kunci: Sistem Operasi; First Come First Serve (FCFS); Round Robin (RR); Algoritma; CPU; Penjadwalan

Abstract-CPU scheduling is important in multitasking and multiprocessing an operating system because of the many processes that need to be run in a computer. This causes the operating system to need to divide resources for running processes. CPU scheduling has several algorithms in it such as First Come First Serve (FCFS), Shortest Job First (SJF), Priority Scheduling, and Round Robin (RR) algorithms. The writing of this study is intended to compare the First Come First Serve and Round Robin algorithms with four specified parameters namely Average Turn Around Time, Waiting Time, Throughput, and CPU Utilization. The experiment was conducted with the First Come First Serve algorithm and the Round Robin of three different Quantum Times. These calculations at different quantum times aim to find out if the differences affect the advantages of the Round Robin algorithm over the First Come First Serve algorithm. The conclusion is that the First Come First Serve (FCFS) algorithm is superior to the Round Robin (RR) algorithm. This is indicated by the average turn around time, waiting time, and throughput values of the First Come First Serve algorithm more effective in running the process.

Keywords: Operating System; First Come First Serve (FCFS); Round Robin (RR); Algorithm; CPU; Schedulling

\section{PENDAHULUAN}

Sistem operasi adalah suatu sistem yang mengatur sumber daya komputer yang diperlukan [5]. Sumber daya yang dikelola oleh sistem operasi dapat berupa memory, perangkat I/O, dan processor. Sistem operasi juga memiliki fungsi untuk mengontrol proses yang berjalan, mengatur data, memfasilitasi input/output, dan lain-lain [5]. Sistem operasi menjalankan tugas sebagai penghubung antara perangkat lunak dan perangkat keras yang digunakan oleh user. Dalam perkembangannya, sistem operasi pada awalnya hanya dapat menjalankan proses tunggal dan sekuensial, berubah menjadi lebih kompleks sehingga dapat menjalankan beberapa proses secara bersamaan (multitasking). Hal tersebut menjadikan memori yang digunakan menjadi lebih efisien.

Penjadwalan proses CPU merupakan bagian dari fungsi dari sistem operasi yang berfungsi untuk mengatur proses-proses yang berjalan pada memory. Penjadwalan CPU merupakan hal yang penting dalam multitasking dan multiprocessing sebuah sistem operasi karena banyaknya proses yang perlu dijalankan dalam komputer. Hal tersebut menyebabkan sistem operasi perlu membagi sumber daya untuk proses-proses yang berjalan [10]. Penjadwalan CPU pada sistem operasi memiliki beberapa algoritma penjadwalan yang berbeda seperti algoritma prioritas, First Come First Serve (FCFS), round robin, dan lain-lain.

Setiap algoritma penjadwalan memiliki kekurangan dan kelebihannya masing-masing. Seperti contohnya algoritma Round Robin yang memiliki Quantum Time yang dapat memengaruhi hasil Throughput, sedangkan pada algoritma First Come First Serve (FCFS) tidak memilki Quantum Time sehingga nilai Throughput-nya bergantung pada burst Time masing-masing proses. Namun, dari keterangan tersebut tidak berarti algoritma Round Robin selalu lebih unggul dari algoritma First Come First Serve, oleh karena itu kita perlu membandingkan setiap algoritmanya, sehingga kita tahu algoritma mana yang lebih unggul dalam penjadwalan CPU.

Pada penelitian terkait yang dilakukan oleh Masrizal [4], perbandingan algoritma First Come First Serve dan Round Robin dilakukan menggunakan aplikasi simulator, kriteria yang diukur pada penelitian tersebut diantaranya adalah Fairness, Utilization, Response Time, dan Turn Around Time. Hasil dari penelitian tersebut yaitu algoritma First Come First Serve lebih unggul daripada Round Robin. Sedangkan pada tulisan ini akan membahas dan melakukan analisis secara mendalam mengenai perbandingan algoritma penjadwalan CPU Round Robin dengan algoritma First Come First Serve untuk mengetahui algoritma mana yang lebih unggul dalam 
Building of Informatics, Technology and Science (BITS)

Volume 3, No 3, December 2021, Page 207-212

ISSN 2684-8910 (media cetak)

ISSN 2685-3310 (media online)

DOI 10.47065/bits.v3i3.1047

penjadwalan CPU dengan melakukan pengukuran terhadap Waiting Time, Turn Around Time, Throughput, dan CPU Utilization.

\section{METODOLOGI PENELITIAN}

\subsection{Tahapan Penelitian}

Penelitian ini dilakukan dengan tujuan untuk menentukan algoritma mana yang lebih memiliki keunggualan dari beberapa indicator yang sudah ditetapkan. Detail tahapan secara keseluruhan yang dilakukan dalam penelitian ini dapat dilihat pada gambar 1 .

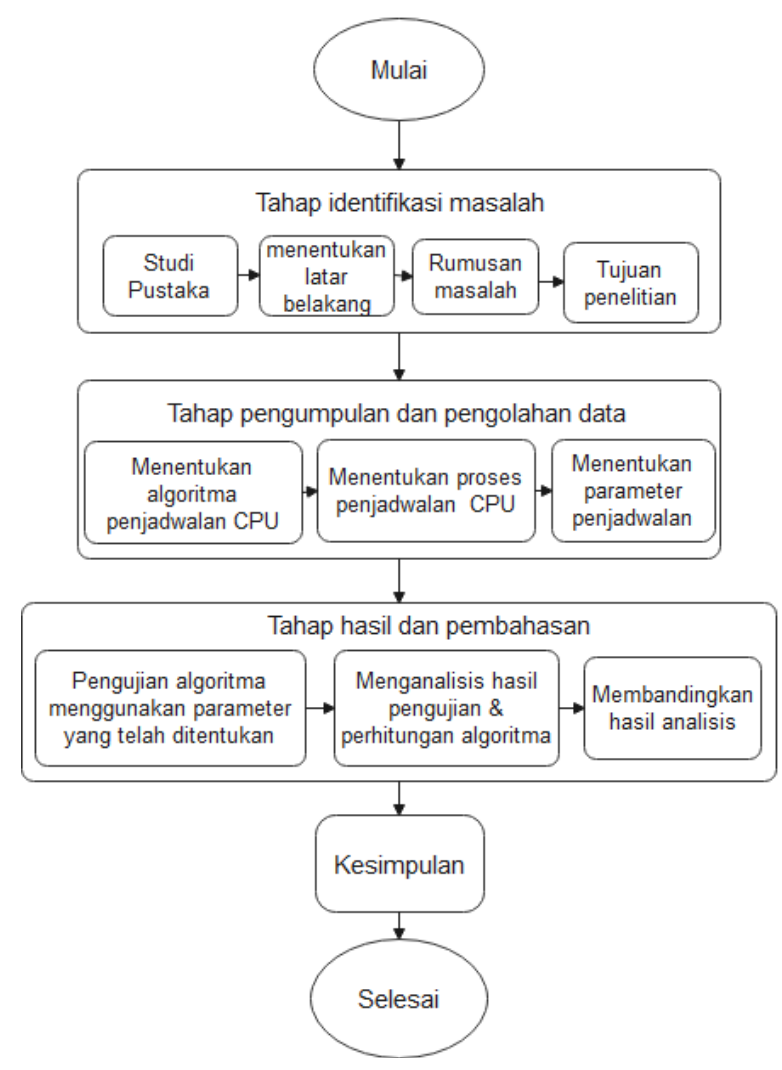

Gambar 1. Diagram alur tahapan penelitian

\subsection{Pengumpulan Data}

Metode pengumpulan data pada penelitian ini yaitu menggunakan studi pustaka. Penulis mengumpulkan sumber literatur yang pembahasannya relevan dengan penelitian ini. Studi pustaka dilakukan untuk memahami algoritma penjadwalan CPU Round Robin dan First Come First Serve, sehingga penulis memiliki pengetahuan terhadap objek yang akan diteliti.

\subsection{Pengujian Algoritma}

Pengujian algoritma digunakan untuk menghitung parameter-parameter yang telah ditentukan dari seluruh proses yang dilakukan oleh CPU.

Parameter yang digunakan dalam pengujian algoritma ini yaitu:

a. Waiting Time : Merupakan waktu suatu proses menunggu gilirannya untuk dieksekusi. Semakin kecil rata-rata Waiting Time suatu proses, maka semakin unggul algoritma tersebut.

b. Turn Around Time : Waktu yang dibutuhkan proses dari waktu proses diteri

c. ma hingga proses selesai. Perhitungan dilakukan dengan menjumlahkan Burst Time dan Waiting Time.Throughput : Banyaknya proses yang berhasil diselesaikan dalam satuan waktu. Throughput dilakukan untuk memaksimalkan seluruh proses yang dikerjakan CPU dalam satuan waktu. Jika dalam satuan waktu, proses yang diselesaikan oleh algoritma semakin banyak, dapat dikatakan bahwa algoritma tersebut lebih unggul.

d. CPU Utilization : Bentuk kriteria dari penjadwalan CPU yang digunakan untuk membuat CPU dalam keadaan sibuk. 


\subsection{Perbandingan Hasil Pengujian}

Tahapan akhir dari penelitian ini adalah dengan membandingkan hasil pengujian algoritma yang telah dilakukan. Perbandingan dilakukan antara algoritma First Come First Serve dengan Round Robin menggunakan 3 kasus yang berbeda berdasarkan dari besar quantum time-nya. Perbedaan besar quantum time dilakukan untuk mengetahui apakah besar quantum time mempengaruhi kinerja dari algoritma Round Robin.

\section{HASIL DAN PEMBAHASAN}

Dalam penelitian ini, analisis dilakukan pada 2 algoritma penjadwalan CPU, yaitu First Come First Serve dan Round Robin. Perhitungan pada algoritma Round Robin dilakukan dengan menggunakan 3 Quantum Time yang berbeda, yaitu:

a. Quantum Time $=4 \mathrm{~ms}$ (batas bawah)

b. Quantum Time $=6 \mathrm{~ms}$ (batas tengah)

c. Quantum Time $=8 \mathrm{~ms}$ (batas atas)

Perhitungan pada Quantum Time yang berbeda ini bertujuan untuk mengetahui apakah perbedaan tersebut memengaruhi keunggulan algoritma Round Robin terhadap algoritma First Come First Serve.

Penjadwalan CPU dilakukan dengan 5 proses yang seluruhnya memiliki arrival time 0 dan burst time yang berbeda-beda seperti yang terdapat pada tabel 1.

Tabel 1. Proses penjadwalan CPU untuk algoritma FCFS \& RR

\begin{tabular}{rrc}
\hline Proses & Arrival Time & Burst Time \\
\hline P1 & 0 & 3 \\
P2 & 0 & 5 \\
P3 & 0 & 11 \\
P4 & 0 & 9 \\
P5 & 0 & 7 \\
\hline
\end{tabular}

\subsection{Gantt Chart First Come First Serve}

Pengujian-1 dilakukan dengan menerapkan algoritma First Come First Serve. Hasil pengujian ditunjukkan pada Tabel 2.

Tabel 2. Hasil Perhitungan Algoritma First Come First Serve (FCFS)

\begin{tabular}{cccccccccccc}
\hline P1 & P2 & P3 & P4 & P5 & P2 & P3 & P4 & P5 & P3 & P4 & \\
\hline 0 & 3 & 7 & 11 & 15 & 19 & 20 & 24 & 258 & 31 & 34 & 35
\end{tabular}

\begin{tabular}{cccccc}
\hline Proses & $\begin{array}{c}\text { Arrival Time } \\
(A T)\end{array}$ & $\begin{array}{c}\text { Burst Time } \\
(B T)\end{array}$ & $\begin{array}{c}\text { Compotition Time }(C T) \\
\text { CT }=\text { Waktu } \\
\text { Proses berakhir }\end{array}$ & $\begin{array}{c}\text { Time Arround } \\
\text { Time }(T A T) \\
\text { TAT }=\text { CT }-A T\end{array}$ & $\begin{array}{c}\text { Waiting Time } \\
(\text { WT })\end{array}$ \\
\hline P1 & 0 & 3 & 3 & 3 & 0 \\
P2 & 0 & 5 & 8 & 8 & 3 \\
P3 & 0 & 11 & 19 & 19 & 8 \\
P4 & 0 & 9 & 28 & 28 & 19 \\
P5 & 0 & 7 & 35 & 35 & 28 \\
& & Average & & $18,6 \mathrm{~ms}$ & $11,6 \mathrm{~ms}$ \\
\hline
\end{tabular}

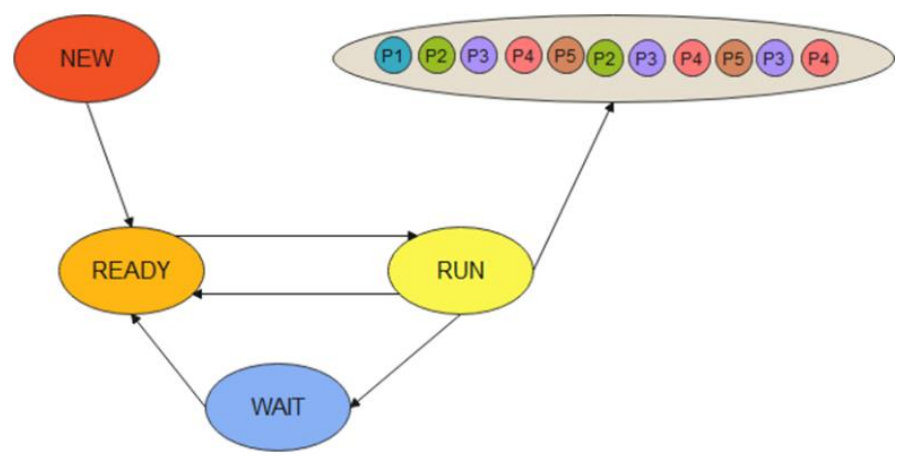

Gambar 2. Diagram status proses dari algoritma FCFS 
Building of Informatics, Technology and Science (BITS)

Volume 3, No 3, December 2021, Page 207-212

ISSN 2684-8910 (media cetak)

ISSN 2685-3310 (media online)

DOI 10.47065/bits.v3i3.1047

\subsection{Gantt Chart Round Robin dengan Quantum Time 4 ms}

Pengujian-2 dilakukan dengan menerapkan algoritma Round Robin dengan Quantum Time 4 ms. Hasil pengujian ditunjukkan pada Tabel 3.

Tabel 3. Hasil Perhitungan Algoritma Round Robin dengan Quantum Time $4 \mathrm{~ms}$

\begin{tabular}{cccccc}
\hline P1 & P2 & P3 & P4 & P5 & \\
\hline 0 & 3 & 8 & 19 & 28 & 35
\end{tabular}

\begin{tabular}{|c|c|c|c|c|c|}
\hline Proses & $\begin{array}{c}\text { Arrival Time } \\
(A T)\end{array}$ & $\begin{array}{l}\text { Burst Time } \\
\text { (BT) }\end{array}$ & $\begin{array}{c}\text { Compotition Time }(C T) \\
C T=\text { Waktu } \\
\text { Proses berakhir }\end{array}$ & $\begin{array}{c}\text { Time Arround } \\
\text { Time }(T A T) \\
T A T=C T-A T\end{array}$ & $\begin{array}{c}\text { Waiting Time } \\
\quad(W T) \\
W T=T A T-B T\end{array}$ \\
\hline P1 & 0 & 3 & 3 & 3 & 0 \\
\hline P2 & 0 & 5 & 20 & 20 & 15 \\
\hline P3 & 0 & 11 & 34 & 34 & 23 \\
\hline P4 & 0 & 9 & 35 & 35 & 26 \\
\hline P5 & 0 & 7 & 31 & 31 & 24 \\
\hline & & Average & & $24,6 \mathrm{~ms}$ & $17,6 \mathrm{~ms}$ \\
\hline
\end{tabular}

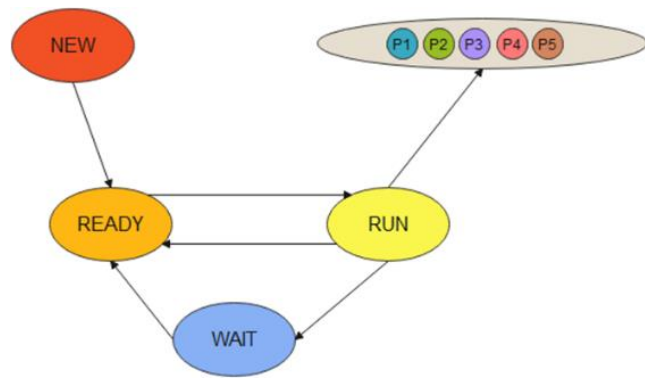

Gambar 3. Diagram status proses dari algoritma RR Quantum Time $4 \mathrm{~ms}$

\subsection{Gantt Chart Round Robin dengan Quantum Time $6 \mathrm{~ms}$}

Pengujian-3 dilakukan dengan menerapkan algoritma Round Robin dengan Quantum Time 6 ms. Hasil pengujian ditunjukkan pada Tabel 4.

Tabel 4. Hasil Perhitungan Algoritma Round Robin dengan Quantum Time $6 \mathrm{~ms}$

\begin{tabular}{ccccccccc}
\hline P1 & P2 & P3 & P4 & P5 & P3 & P4 & P5 & \\
\hline 0 & 3 & 8 & 14 & 20 & 26 & 31 & 34 & 35
\end{tabular}

\begin{tabular}{cccccc}
\hline Proses & $\begin{array}{c}\text { Arrival Time } \\
(A T)\end{array}$ & $\begin{array}{c}\text { Burst Time } \\
(B T)\end{array}$ & $\begin{array}{c}\text { Compotition Time }(C T) \\
\text { CT }=\text { Waktu } \\
\text { Proses berakhir }\end{array}$ & $\begin{array}{c}\text { Time Arround } \\
\text { Time }(\text { TAT })\end{array}$ & $\begin{array}{c}\text { Waiting Time } \\
\text { TAT }=\text { CT }- \text { AT }\end{array}$ \\
WT $=$ WAT - BT \\
\hline P1 & 0 & 3 & 3 & 3 & 0 \\
P2 & 0 & 5 & 8 & 8 & 3 \\
P3 & 0 & 11 & 31 & 31 & 20 \\
P4 & 0 & 9 & 34 & 34 & 25 \\
P5 & 0 & 7 & 35 & 35 & 28 \\
& & Average & & $22,2 \mathrm{~ms}$ & $15,2 \mathrm{~ms}$ \\
\hline
\end{tabular}

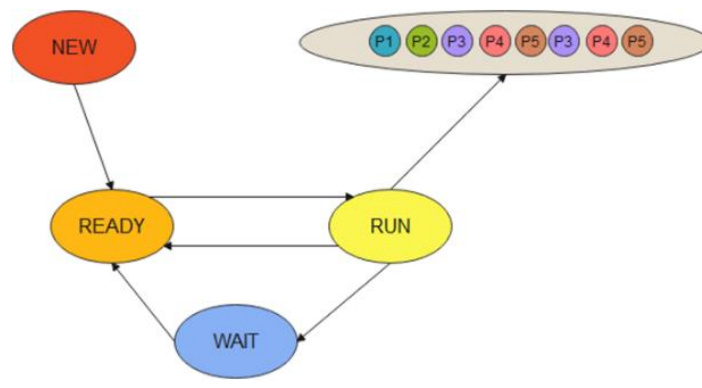

Gambar 4. Diagram status proses dari algoritma RR Quantum Time $6 \mathrm{~ms}$ 
Building of Informatics, Technology and Science (BITS)

Volume 3, No 3, December 2021, Page 207-212

ISSN 2684-8910 (media cetak)

ISSN 2685-3310 (media online)

DOI 10.47065/bits.v3i3.1047

\subsection{Gantt Chart Round Robin dengan Quantum Time $8 \mathrm{~ms}$}

Pengujian-4 dilakukan dengan menerapkan algoritma Round Robin dengan Quantum Time 8 ms. Hasil pengujian ditunjukkan pada Tabel 5 .

Tabel 5. Setting parameter pengujian pada penelitian ini.

\begin{tabular}{cccccccc}
\hline P1 & P2 & P3 & P4 & P5 & P3 & P4 & \\
\hline 0 & 3 & 8 & 16 & 24 & 31 & 34 & 35
\end{tabular}

\begin{tabular}{cccccc}
\hline Proses & $\begin{array}{c}\text { Arrival Time } \\
(A T)\end{array}$ & $\begin{array}{c}\text { Burst Time } \\
(B T)\end{array}$ & $\begin{array}{c}\text { Compotition Time }(C T) \\
\text { CT }=\text { Waktu } \\
\text { Proses berakhir }\end{array}$ & $\begin{array}{c}\text { Time Arround } \\
\text { Time }(\text { TAT }) \\
\text { TAT }=\text { CT }-A T\end{array}$ & $\begin{array}{c}\text { Waiting Time } \\
\text { (WT) }\end{array}$ \\
& & & 3 & 3 & WAT - BT \\
\hline P1 & 0 & 3 & 8 & 8 & 0 \\
P2 & 0 & 5 & 34 & 34 & 3 \\
P3 & 0 & 11 & 35 & 35 & 23 \\
P4 & 0 & 9 & 31 & 31 & 24 \\
P5 & 0 & 7 & & $22,2 \mathrm{~ms}$ & $15,2 \mathrm{~ms}$ \\
& & Average & & & \\
\hline
\end{tabular}

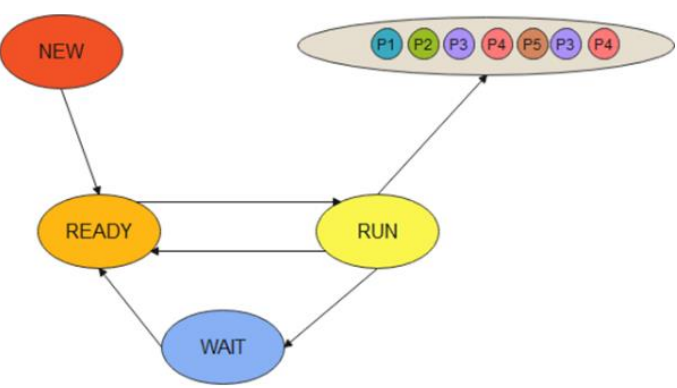

Gambar 5. Diagram status proses dari algoritma RR Quantum Time $8 \mathrm{~ms}$

Berdasarkan hasil analisis perhitungan setiap algoritma yang telah dilakukan, maka dapat dibuat perbandingan seperti yang ditunjukkan pada Tabel 6

Tabel 6. Hasil Perbandingan

\begin{tabular}{ccccc}
\hline Algoritma & $\begin{array}{c}\text { Average Turn } \\
\text { Around Time }\end{array}$ & $\begin{array}{c}\text { Average } \\
\text { Waiting Time }\end{array}$ & $\begin{array}{c}\text { Throughput } \\
17,5 \mathrm{~ms}\end{array}$ & CPU Utilization \\
\hline First Come First Serve & 18,6 & 11,6 & 2 & $100 \%$ \\
Round Robin $(\mathrm{QT}=4)$ & 24,6 & 17,6 & 1 & $100 \%$ \\
Round Robin $(\mathrm{QT}=6)$ & 22,2 & 15,2 & 2 & $100 \%$ \\
Round Robin $(\mathrm{QT}=8)$ & 22,2 & 15,2 & 2 & $100 \%$
\end{tabular}

Hasil perbandingan dari analisis perhitungan setiap algoritma menunjukkan bahwa dari setiap parameter yang ditentukan, algoritma First Come First Serve (FCFS) lebih unggul dibandingkan algoritma Round Robin (RR) dilihat dari hasil average turn around time dan average waiting time yang nilainya lebih kecil. Throughput atau proses yang diselesaikan dalam satuan waktu pada algoritma FCFS bernilai sama dengan algoritma RR quantum time 6 dan 8 yaitu menyelesaikan 2 proses dalam waktu 17,5 ms, tetapi throughput pada algoritma RR quantum 4 menyelesaikan 1 proses dalam waktu 17,5 ms. Throughput setiap algoritma dalam mengerjakan setiap proses sampai selesai adalah $17,5 \mathrm{~ms}$ yang didapat dari nilai tengah total Burst Time proses. CPU Utilization pada semua algoritma menunjukkan hasil yang sama karena CPU selalu dalam keadaan sibuk sampai selesai menjalankan proses.

Setelah dilakukan perhitungan dan perbandingan antara algoritma FCFS dengan dengan menggunakan 3 nilai Quantum Time yang berbeda dari algoritma Round Robin, dihasilkan bahwa algoritma FCFS tetap lebih unggul daripada algoritma Round Robin. Oleh karena itu dapat dikatakan bahwa besar dari nilai Quantum Time dari algoritma Round Robin tidak menghasilkan algoritma yang lebih unggul dari pada algoritma First Come First Serve.

\section{KESIMPULAN}

Dari hasil penelitian ini kesimpulan yang didapatkan adalah bahwa algoritma First Come First Serve (FCFS) lebih unggul dari algoritma Round Robin (RR). Hal tersebut ditunjukkan dengan nilai rata-rata Turn Around Time, 
Building of Informatics, Technology and Science (BITS)

Volume 3, No 3, December 2021, Page 207-212

ISSN 2684-8910 (media cetak)

ISSN 2685-3310 (media online)

DOI 10.47065/bits.v3i3.1047

Waiting Time, dan Throughput dari algoritma First Come First Serve lebih efektif dalam menjalankan proses. CPU Utilization pada setiap algoritma menunjukkan hasil yang sama, karena CPU terus menjalankan prosesnya sampai selesai (CPU selalu dalam keadaan sibuk). Throughput setiap algoritma dalam mengerjakan setiap proses sampai selesai adalah 17,5 ms yang didapat dari nilai tengah total Burst Time proses. Setelah dilakukan perhitungan dan perbandingan antara algoritma First Come First Serve dengan menggunakan 3 nilai quantum time yang berbeda, didapatkan hasil yaitu perbedaan dari besar nilai quantum dari algoritma Round Robin tidak menghasilkan algoritma yang lebih unggul daripada algoritma First Come First Serve.

\section{UCAPAN TERIMAKASIH}

Terima kasih disampaikan kepada Kampus Universitas Pendidikan Indonesia di Cibiru dan kepada Program Studi Teknik Komputer yang sudah memberikan dukungan.

\section{REFERENCES}

[1] Fratiwi, D., \& Mariana, N. (2020). Metode Fcfs Dalam Menunjang Sistem Layanan Antrian Pembagian Dana Pensiun Studi Kasus Kantor Pos Bongsari. Proceeding SENDIU, 978-979.

[2] Hadi, R., \& Nugrahaeni, Y. (2016). Aplikasi Penjadwalan Terapi dengan Metode FCFS pada Sixo Reflexology. Journal of Applied Intelligent System, 1(2), 134-143. http://publikasi.dinus.ac.id/index.php/jais/article/view/1190/894

[3] Harki, N., Ahmed, A., \& Haji, L. (2020). CPU Scheduling Techniques: A Review on Novel Approaches Strategy and Performance Assessment. Journal of Applied Science and Technology Trends, 1(2), 48-55. https://doi.org/10.38094/jastt1215

[4] Masrizal (2017). Simulasi Perbandingan Penjadwalan Round Robin dan FCFS untuk Manajemen Proses dalam Single Processing. Jaringan Sistem Informasi Robotik, 1.

[5] Putra, T. D., \& Purnomo, R. (2021). Analisis Algoritma Round Robin pada Penjadwalan CPU. Jurnal Ilmiah Teknologi Informasi Asia, 15(2), 85-90.

[6] Rajput, I. S., \& Gupta, D. (2012). A Priority based Round Robin CPU Scheduling Algorithm for Real Time Systems. Journal of Advanced Engineering Technologies, 1(3), 1-11.

[7] Riadi, S., \& Ulum, F. (2021). ANALISIS PENERAPAN ALGORITMA FIRST COME FIRST SERVED ( FCFS ) DALAM PROSES PESANAN PADA APLIKASI GOJEK. 2(2), 268-275.

[8] Santika, M., \& Hansun, S. (2014). Implementasi Algoritma Shortest Job First dan Round Robin pada Sistem Penjadwalan Pengiriman Barang. Jurnal ULTIMATICS, 6(2), 94-99. https://doi.org/10.31937/ti.v6i2.336

[9] Sofiansyah Fadli, Maulana Ashari, K. I. (2020). 136-13-1117-1-10-20200714. Sistem Penjadwalan Event Organizer Dengan Metode Round Robin (Rr), 3(2).

[10] Wijaya, A., Gunawan (2018). Implementasi Algoritma Round Robin Pada Sistem Penjadwalan Mata Kuliah (Studi Kasus: Universitas Muhammadiyah Bengkulu). JURNAL INFORMATIKA UPGRIS Vol. 4, No.1, 65 